Research Article

\title{
Research on Fault Activation Law in Deep Mining Face and Mechanism of Rockburst Induced by Fault Activation
}

\author{
Lyu Pengfei $\mathbb{D}^{1},{ }^{1}$ Bao Xinyang, ${ }^{2}$ Lyu Gang, ${ }^{2}$ and Chen Xuehua ${ }^{3}$ \\ ${ }^{1}$ Mining Research Institute, Inner Mongolia University of Science and Technology, Inner Mongolia Autonomous Region 014010, \\ Baotou, China \\ ${ }^{2}$ Shenyang Coking Coal Co., Ltd., Hongyang No.3 Coal Mine, Dengta, Liaoning 111300, China \\ ${ }^{3}$ College of Mining, Liaoning Technical University, Fuxin, Liaoning 123000, China \\ Correspondence should be addressed to Lyu Pengfei; 2018930@imust.edu.cn
}

Received 21 July 2020; Revised 15 October 2020; Accepted 13 November 2020; Published 30 November 2020

Academic Editor: Fengqiang Gong

Copyright (C) 2020 Lyu Pengfei et al. This is an open access article distributed under the Creative Commons Attribution License, which permits unrestricted use, distribution, and reproduction in any medium, provided the original work is properly cited.

\begin{abstract}
To effectively monitor and control the severe mining-induced rockburst in deep fault area, the fault activation law and the mechanical essence of rockburst induced by crossing fault mining were studied through theoretical analysis, microseismic monitoring, field investigation, and other methods; numerical simulation was employed to verify the obtained fault activation law and the mechanical nature. First, the distribution of microseismic sources at different mining locations and the fault activation degree were analyzed. According to the microseismic frequency and the characteristics of the energy stage, the fault activation degree was divided into three stages: fault stress transfer, fault pillar stress behavior, and fault structure activation. It was determined that the impact disaster risk was the strongest in the stage of the fault pillar stress behavior. Based on the periodic appearance law of microseisms in fault area, three types of conceptual models of fault-type rockburst were proposed, and the rockburst carrier system model of "roof-coal seam-floor" in the fault area was established. The mechanical essence of fault-type rockburst was obtained as follows: under the action of fault structure, the static load of the fault coal pillar was increased and superimposed with the active dynamic load of the fault, leading to high-strength impact disaster. Finally, the prevention and treatment concepts of fault-type rockburst were proposed. The monitoring and prevention measures of fault-type rockburst were taken from two aspects: the monitoring and characterization of fault rockburst and weakening control of the high static load of the fault coal pillar and dynamic load of fault activation. The proposed concepts and technical measures have been verified in the working face 14310 of Dongtan Coal Mine with sound results. The research results have a guiding significance for the prevention and control of rockburst in a similar mining face under crossing fault mining.
\end{abstract}

\section{Introduction}

By 2019, 187 coal mines in China have been identified as being at risk of rockburst, and 17 mines distributing in 26 provinces have experienced rockburst hazards. Rockburst has become a key problem threatening coal mine safety $[1,2]$. Mines with the proneness of rockburst are usually characterized by the large depth of coal seams, large coal thickness, complex structure, and hard roof [3-6]. In the tectonic zone, the elastic-plastic deformation energy of coal and rock mass is unevenly distributed. In the stress concentration area, affected by the mining activities, the energy of coal and rock can be released suddenly, leading to the rockburst $[7,8]$. Moreover, the collapsing force of the rock induced by fault activation is much greater [9]. Figure 1 shows the actual situation after the fault-type rockburst hazard.

Faults and joints widely exist in underground rock mass and directly affect the macromechanical properties of rock mass, such as load resistance, deformation capacity, and shear strength $[10,11]$. When faults are encountered in the mining face, the stress distribution and surrounding rock failure are different from those in the conventional working face. There is no fixed low in stress accumulation and energy release of the working face affected by fault mining activation, and the sudden release of energy can easily cause the 


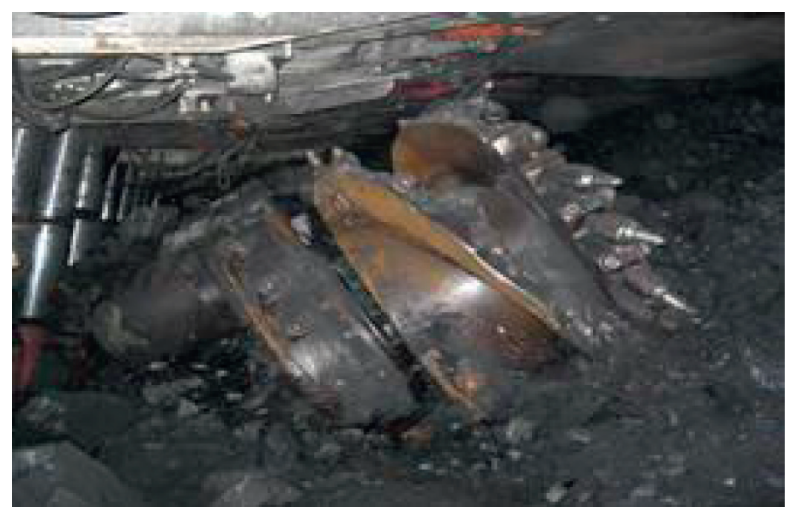

(a)

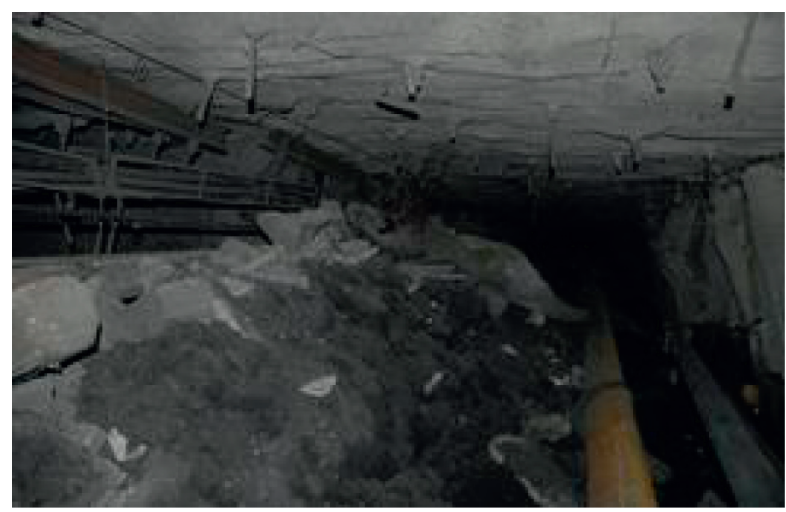

(c)

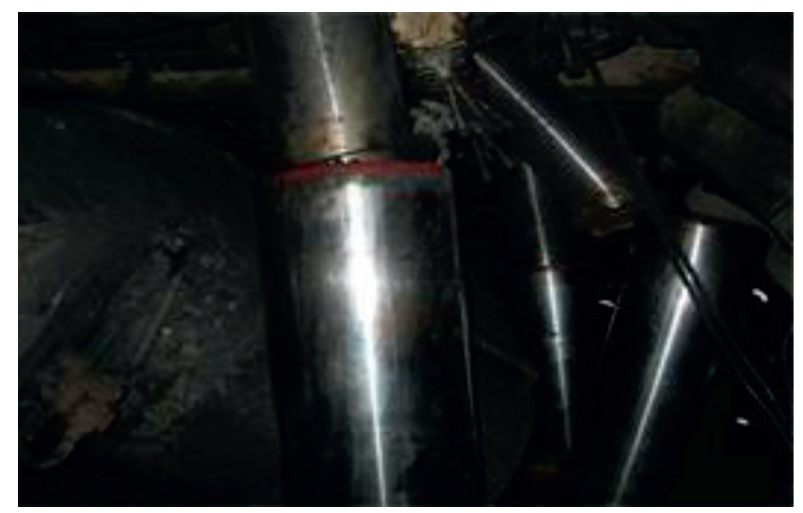

(b)

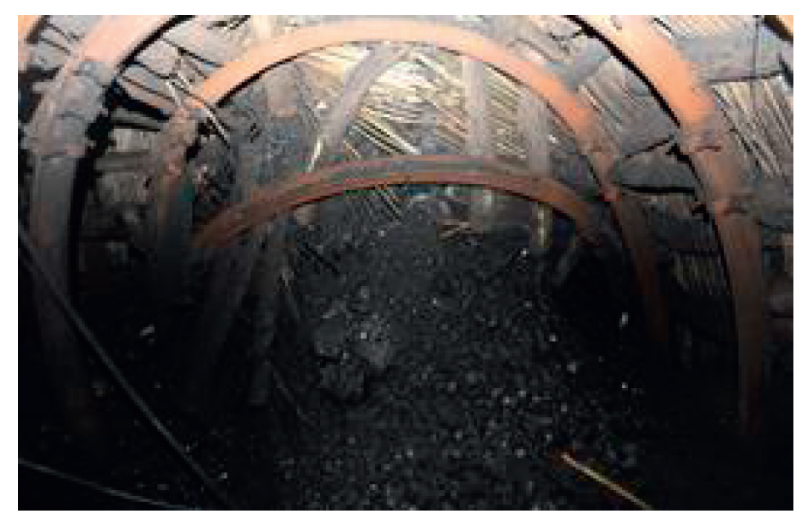

(d)

Figure 1: Damaged condition of rockburst hazards. (a) Shearer collapsed. (b) Pillar bent. (c) Floor plucked. (d) Broken coal in roadway.

impact instability of coal and rock mass and even lead to impact disaster. Therefore, accurately grasping the activation law of the mining-induced fault is the necessary premise for the prevention and control of fault-type rockburst.

At present, the theoretical model, field monitoring, numerical simulation, and test method are mainly used in the research on the law of mining-induced fault activation and the rockburst-induced mechanism. For theoretical models, many mechanical models and discriminant criteria have been established, such as the rockburst stick-slip instability criterion [12], fault disturbance response instability criterion [13], instability model of the coal rock dynamic system in the structural area [14], and impact instability model of the fault coal pillar [15]. In terms of the rock test and numerical simulation, $S i$ et al. [16] studied the influence of the unloading rate on the occurrence mechanism of rockburst through the triaxial compression test of granite. It was found that under the same surrounding rock pressure, the lower unloading rate was conducive to improving the peak strength of rock and the accumulation of elastic energy, while the existence of the fault in mining face hindered the stress transmission; then, the unloading rate of coal and rock mass was reduced. As a result, the rockburst in a higher intensity can be induced. Through the granite triaxial compression test, Gong et al. [17] also analyzed the fracture evolution process of the prefabricated granite specimen under different three-dimensional stress conditions. The results showed that when the vertical stress was constant and the horizontal stress increased, the fracture strength of the specimen increased obviously; however, when the fault was formed, large horizontal stress was easily accumulated near the fault. As a result, the stress condition of rockburst was undoubtedly worsened, and the strength of rockburst in the fault area was larger. Manouchehrian et al. [18] discussed the influence of fault size, dip angle, and direction on tunnel rock failure by using heterogeneous explicit program software Abaqus ${ }^{2 \mathrm{D}}$ and confirmed the fault action conditions in the process of rockburst through numerical inversion of actual rockburst cases. Based on the numerical calculation results of FLAC ${ }^{3 \mathrm{D}}$, Jiang et al. $[19,20]$ and Wang et al. $[21,22]$ analyzed the influence of fault dip angle and mining direction on fault activation and obtained the movement characteristics of the hard and thick roof in the fault area and the occurrence law of rockburst. Luo et al. [23] simulated and analyzed the evolution law of the stress field and displacement field of the deep working face adjacent to the fault. When a working face with a thickness of $5 \mathrm{~m}$ was $35 \mathrm{~m}$ away from the fault, the maximum fault activation strength was obtained. In terms of field monitoring, Michael et al. [24] captured the precursor information of fault rockburst by using microseismic monitoring and considered that the surrounding rock often experienced 3-5 days of the energy storage period before the occurrence of rockburst. Ma et al. [25] studied the influence of fault activation on the vertical zoning of overlying strata based on microseismic monitoring and stress inversion. He et al. [26, 27] analyzed the law 
of dynamic load release in the fault activation combined with microseismic and stress data and established the evaluation method of fault rockburst.

The above studies mainly focus on fault activation and the occurrence of rockburst in the working face adjacent to the fault. The stress evolution and vibration energy release characteristics of fault planes are mainly analyzed. However, research on the fault activation process caused by the crossing fault mining in deep thick-coal seam and the mechanical nature of rockburst has been rarely performed. Based on the mining crossing NF6 fault in working face 14310 of Dongtan Coal Mine, theoretical analysis, microseismic monitoring, and numerical simulation were performed in this paper. The fault activation, vibration energy release, and rock stress evolution law during the crossing fault mining were analyzed, and the near-fault coal rock system model of coal seam-roof-floor was established to reveal the nature of rockburst induced by fault activation. This study provides the guidance for the prevention and control of rockburst in the crossing fault mining.

\section{Microseismic Behavior Law of Crossing Fault Mining}

2.1. Overview of the Working Face. The working face 14310 of Dongtan Coal Mine was located in the north of the No.14 mining area in Yanzhou, China. Working face 14310 was adjacent to the goaf on the one side and solid coal in the other side. No.3 coal seam was mined in the working face. The coal seam structure was simple; the thickness was 7.4-10.2 m, with an average of $9 \mathrm{~m}$; the strike length was $991 \mathrm{~m}$; the inclined width was $263 \mathrm{~m}$; the coal seam dip angle was $0-6^{\circ}$, with the average of $3^{\circ}$; the buried depth of coal seam was $582-615 \mathrm{~m}$, with an average of $605 \mathrm{~m}$. The fully mechanized sublevel caving technology was used for the mining. The NF6 normal fault was developed along with coal seam tendency and $629 \mathrm{~m}$ away from the open-off cut in the middle of the working face. The exposed drop of the headentry was $2.8 \mathrm{~m}$ with an inclination of $57^{\circ}$, and the exposed drop of the tailentry was $3.4 \mathrm{~m}$ with an inclination of $65^{\circ}$, as shown in Figure 2. The fault ran through the whole working face along the strike with a large drop. Empirically, when the mining was advanced close to the fault, the ground pressure within $150 \mathrm{~m}$ before and after the fault was strong, and the dynamic phenomena such as spalling and roof fall were easy to occur.

2.2. Microseismic Source Distribution Law in Mining. The microseismic system was installed in working face 14310 to effectively capture the information of surrounding rock fracture and fault activation. A group of geophones with a frequency of $30-2000 \mathrm{~Hz}$ were arranged at an interval of $50 \mathrm{~m}$ from the open-off cut in the headentry and tailentry of the working face, as shown in Figure 2. More than 6 geophones were used to ensure the effective monitoring of the movement of surrounding rock at the same time.

The microseismic sources were monitored during the mining period from $300 \mathrm{~m}$ to $-50 \mathrm{~m}$ from the fault in

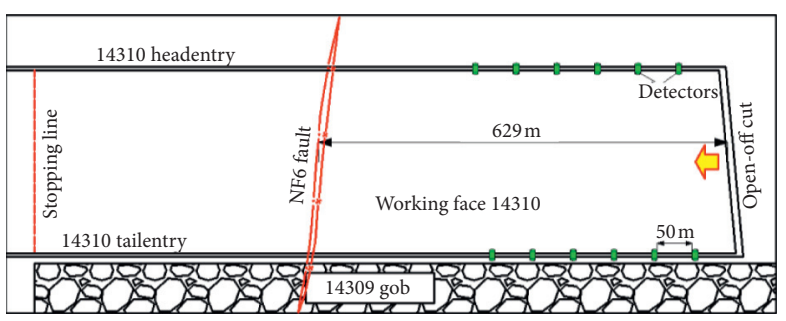

FIGURE 2: Plane figure of working face 14310.

working face 14310 and projected horizontally on the plane, as shown in Figure 3 (due to a large number of microseisms, only microseisms with energy greater than $100 \mathrm{~J}$ were displayed). As shown in Figure 3(a), when the coal wall was $268 \mathrm{~m}-178 \mathrm{~m}$ away from the fault, the seismic source distribution was consistent with that without the fault in front of the working face, that is, low-energy microseisms accounted for the majority in front of the working face front and goaf. The seismic source distribution was $81 \mathrm{~m}$ outside the transportation roadway of the working face, $104 \mathrm{~m}$ outside the tailgate, and $139 \mathrm{~m}$ in front of the working face. There was no seismic source near the fault, indicating that the mining fault in this stage has not been activated. As shown in Figure 3(b), when the coal wall was 178 m-155 m away from the fault, low-energy microseisms occurred near the fault, and the seismic source position was on the fault plane. In addition, a small amount of fault mud gushed from the fault during the field investigation. It indicates that the fault has begun to activate under the influence of mining, but the activation degree was not significant. As shown in Figure 3(c), when the coal wall was $155 \mathrm{~m}-62 \mathrm{~m}$ away from the fault, there were microseisms on the hanging wall and footwall of the fault and the fault surface. The frequency and energy of microseisms near the fault increased, and there were four microseisms with an energy greater than $5 \times 10^{4} \mathrm{~J}$. It indicates that the fault was in continuous activation, and the activation degree was gradually intensified. In addition, the advanced influence range of normal mining in working face 14310 was $139 \mathrm{~m}$, and when there was a fault in front of the coal wall, the advanced influence range was $196 \mathrm{~m}$. The source points farthest from the working face in Figures 3(a) and 3(c) were generated when the working face was mined to the green straight line position. Thus, the advanced influence range of the working face was the distance from the green straight line to the farthest focal point. When the fault was formed, a large amount of tectonic stress (mainly horizontal stress) accumulated on both sides of the fault. Under the disturbance of mining, the fault stress had a sudden change (the release of tectonic stress). Under the superposition of mining stress, the possibility of inducing rockburst was further increased. As shown in Figure 3(d), when the coal wall was $62 \mathrm{~m}-18 \mathrm{~m}$ to the fault, a large number of microseisms appeared near the fault, and the proportion of high-energy microseisms increased significantly. It indicates that the activation degree of the fault increased again. The same conclusion was also obtained from the monitoring results of borehole stress at $4.5 \mathrm{~m}$ away from the fault in the tailentry, as shown in Figure 4. During the four consecutive 

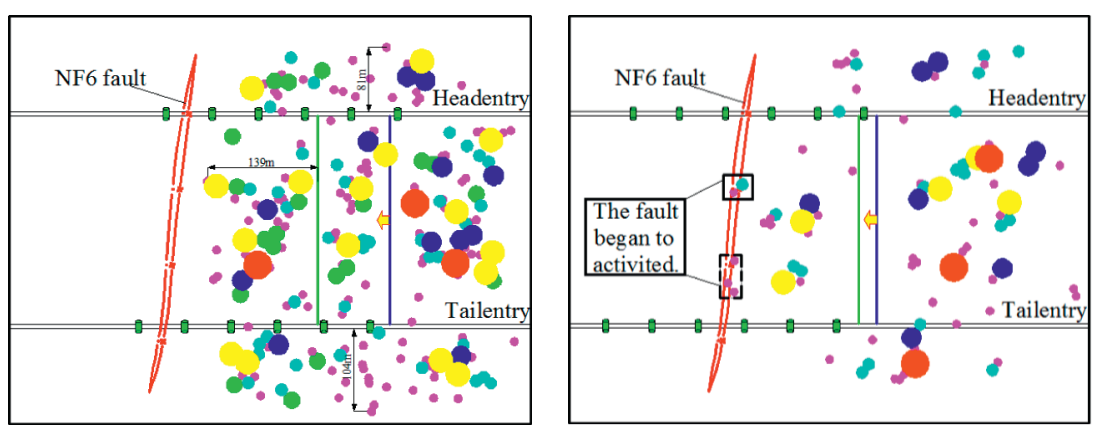

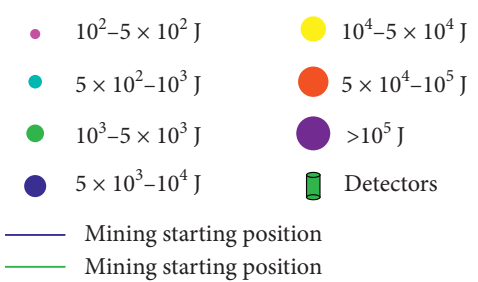

(a)
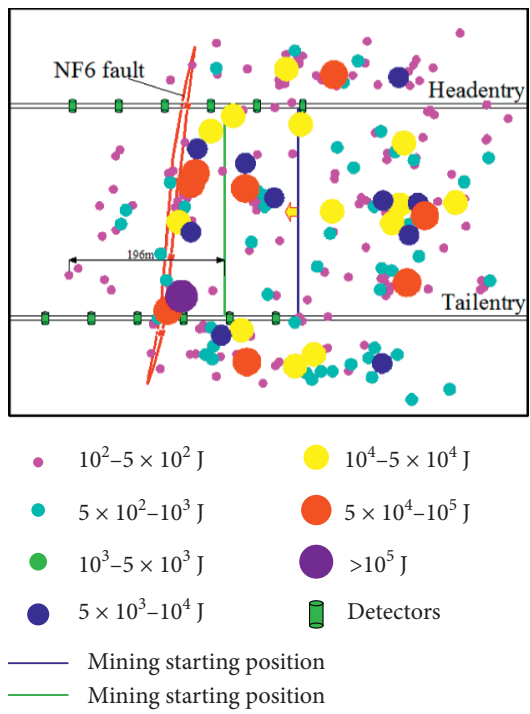

(c)

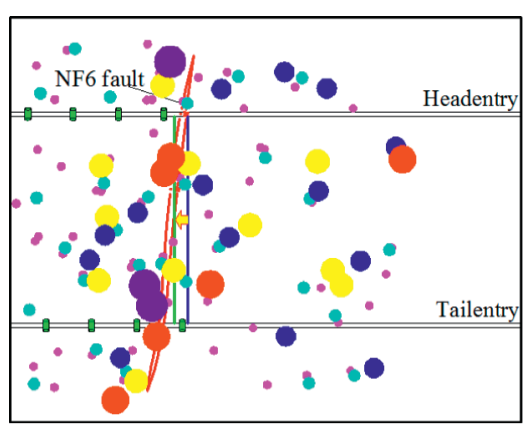

- $10^{2}-5 \times 10^{2} \mathrm{~J}$

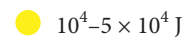

- $5 \times 10^{2}-10^{3} \mathrm{~J}$

$5 \times 10^{4}-10^{5} \mathrm{~J}$

- $10^{3}-5 \times 10^{3} \mathrm{~J}$

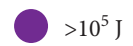

- $5 \times 10^{3}-10^{4} \mathrm{~J}$

b. Detectors

Mining starting position Mining starting position

(e)

$$
\begin{aligned}
& \text { - } 10^{2}-5 \times 10^{2} \mathrm{~J} \quad 10^{4}-5 \times 10^{4} \mathrm{~J} \\
& \text { - } 5 \times 10^{2}-10^{3} \mathrm{~J} 5 \times 10^{4}-10^{5} \mathrm{~J} \\
& \text { - } 10^{3}-5 \times 10^{3} \mathrm{~J}>10^{5} \mathrm{~J} \\
& \text { - } 5 \times 10^{3}-10^{4} \mathrm{~J} \text { Detectors } \\
& \text { Mining starting position } \\
& \text { Mining starting position }
\end{aligned}
$$

(b)

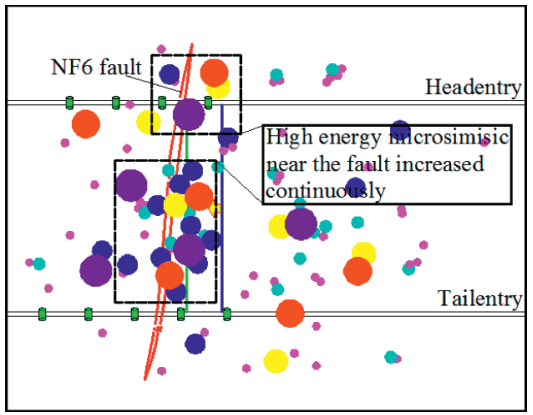
- $10^{2}-5 \times 10^{2} \mathrm{~J}$
$10^{4}-5 \times 10^{4} \mathrm{~J}$
- $5 \times 10^{2}-10^{3} \mathrm{~J}$
$5 \times 10^{4}-10^{5} \mathrm{~J}$
- $10^{3}-5 \times 10^{3} \mathrm{~J}$
$>10^{5} \mathrm{~J}$
- $5 \times 10^{3}-10^{4} \mathrm{~J}$
[. Detectors
_ Mining starting position Mining starting position

(d)

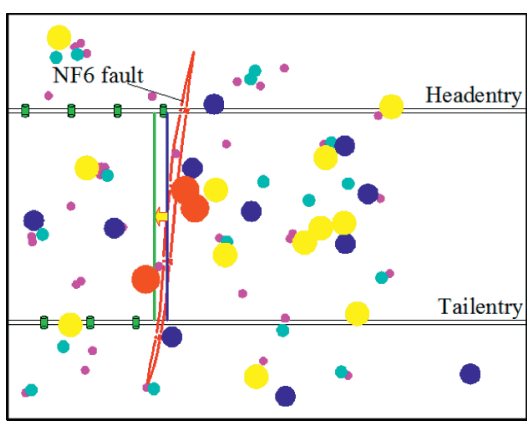
- $10^{2}-5 \times 10^{2} \mathrm{~J}$
$10^{4}-5 \times 10^{4} \mathrm{~J}$
- $5 \times 10^{2}-10^{3} \mathrm{~J}$
$5 \times 10^{4}-10^{5} \mathrm{~J}$
- $10^{3}-5 \times 10^{3} \mathrm{~J}$
$>10^{5} \mathrm{~J}$
- $5 \times 10^{3}-10^{4} \mathrm{~J}$
[. Detectors
Mining starting position Mining starting position

(f)

Figure 3: Continued. 


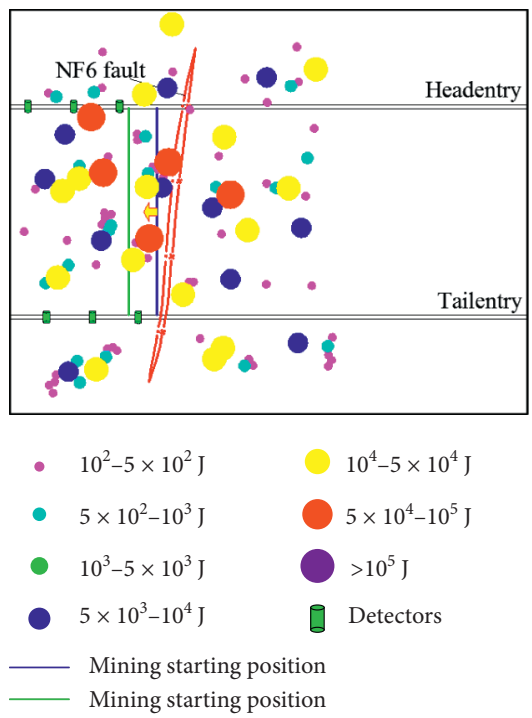

(g)

FIgURe 3: Microseismic distribution in working face 14310 (June 20 to August 20). (a) The distance between the working face and fault is $268 \mathrm{~m}-178 \mathrm{~m}$. (b) The distance between the working face and fault is $178 \mathrm{~m}-155 \mathrm{~m}$. (c) The distance between the working face and fault is $155 \mathrm{~m}-62 \mathrm{~m}$. (d) The distance between the working face and fault is $62 \mathrm{~m}-18 \mathrm{~m}$. (e) The distance between the working face and fault is $18 \mathrm{~m}-0 \mathrm{~m}$. (f) The distance between the working face and fault is $0 \mathrm{~m}-16 \mathrm{~m}$. (g) The distance between the working face and fault is $16 \mathrm{~m}-51 \mathrm{~m}$. (h) Legend.

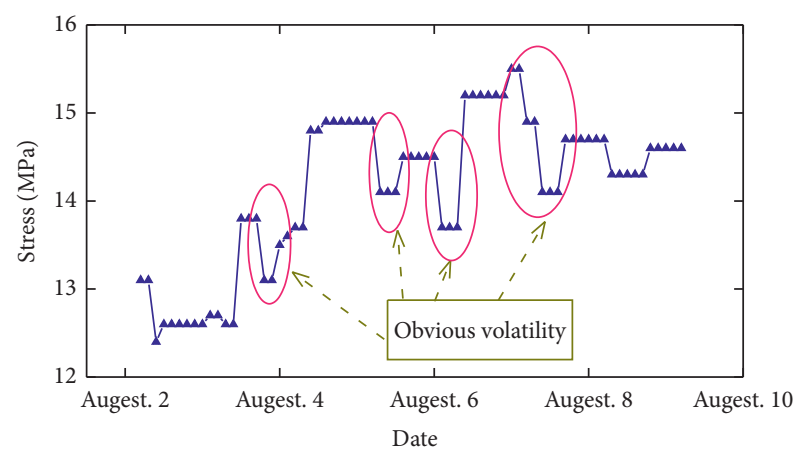

FIgURE 4: Borehole stress monitoring results.

days (from August 3 to August 6), the fluctuation of borehole stress data was extremely strong, and the phenomenon of sudden increase and drop of stress was significant, which was also the result of unbalanced release of fault activation stress. At this stage, the fault was close to the coal wall, among which the rock mass acted as the coal pillar due to the cutting effect of the fault. The rotary subsidence of overlying strata compressed the fault coal pillar and induced a large number of and high-energy microseisms, which greatly increased the possibility of rockburst. As shown in Figure 3(e), when the coal wall was $18 \mathrm{~m}-0 \mathrm{~m}$ to the fault, the high-energy microseisms decreased, but there were still 8 high-energy microseisms (in coal mine engineering practice, microseisms with energy greater than $5 \times 10^{4} \mathrm{~J}$ were often referred to as high-energy microseisms), and all the sources were near the fault plane. This is because the working face was close to the fault, and the fault has been activated for a long time. Under the influence of mining, the relative movement trend of the hanging wall and footwall of the fault increases, which may induce the rockburst. As shown in Figure 3(f), when the working face passed through the fault of $0-16 \mathrm{~m}$, the frequency and energy of microseisms decreased significantly; there were three high-energy microseisms, which may be caused by the residual stress of fault activation. As shown in Figure 3(g), when the working face passed through the fault of $16-51 \mathrm{~m}$, the microseisms returned to be normal, and the safe crossing fault mining has been realized in the working face.

2.3. Periodic Appearance Law of Microseisms. Figure 5 shows the microseismic periodic curve of working face 14310. It can be seen that the frequency and energy amplitude of microseisms has a significant stage change. Based on this, fault activation can be divided into three stages: (1) fault stress transfer: due to the large tectonic stress near the fault, when the working face was far away from the fault $(155 \mathrm{~m}-62 \mathrm{~m})$, the tectonic stress mainly composed of horizontal stress was gradually released and transferred. Under the influence of mining, the stress of coal and rock mass between the working face and the fault accumulated, and the frequency and energy amplitude of microseisms increased compared with normal mining. In this stage, the frequency and energy of microseisms fluctuated to a certain extent, but they were still dominated by small-energy microseisms. Therefore, the fracture of the coal and rock at this stage belonged to the microfracture. (2) Fault pillar stress behavior: the distance between the fault and working face decreased with the mining $(62 \mathrm{~m}-18 \mathrm{~m})$. In addition, the fault cutoff the continuity of the coal seam and roof, and the fault pillar was formed. Under the joint action of mining, 


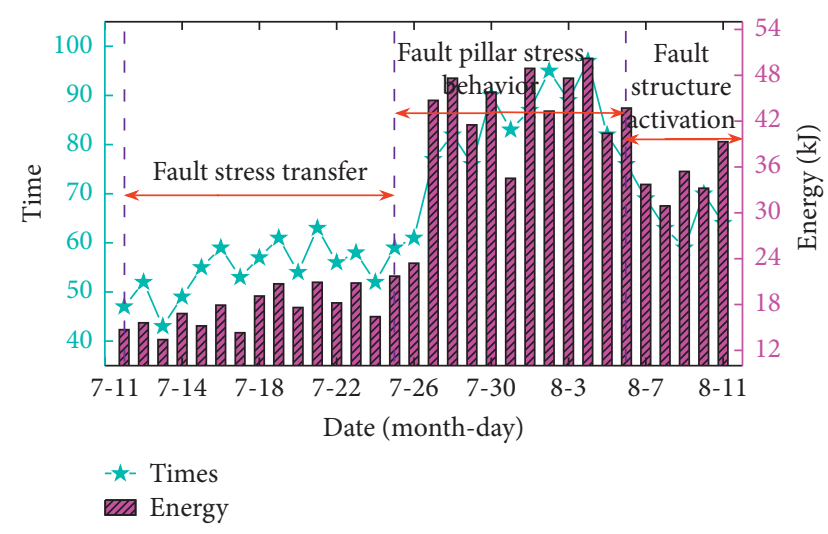

Figure 5: Stage curve of microseisms in fault-crossing mining.

fault activation, and fault pillar, yield failure occurred and large energy was released. Therefore, the frequency and energy amplitude of microseisms significantly increased compared with that in the stage of fault stress transfer, and the impact risk was increased. In addition, the frequency and energy of microseisms increased sharply and decreased sharply. For example, the frequency and energy of microseisms on July 30 were greatly reduced and then increased again. It is speculated that the energy storage of coal and rock mass often occurred before the high-energy microseisms. (3) Fault structure activation: when the working face was close to the fault $(18 \mathrm{~m}-0 \mathrm{~m})$, the movement of the fault plane was enhanced under the long-term activation. The support pressure transmitted to the fault planes overlapped with the tectonic stress near the fault, which may overcome the friction resistance of the fault planes, and the hanging wall and footwall of the fault were forced to move relatively. The microseismic frequency and energy amplitude were medium, and the instability tended to increase. This may be caused by the friction and sliding of local coal and rock mass due to the serious activation of fault structure. The daily average vibration frequency and daily vibration energy of the three stages were compared as follows: 55 and $17918 \mathrm{~J}$ in the stage of fault stress transfer, 85 and $44382 \mathrm{~J}$ in the stage of fault pillar stress behavior; and 66 and $34507 \mathrm{~J}$ in the stage of the fault structure activation stage. Therefore, the strength of the induced rockburst in the three stages was ranged in the descending order: fault pillar stress behavior, fault structure activation, and fault stress transfer. This finding can be used to guide the investment in the prevention and control of rockburst.

\subsection{Fault Activation Correlation and Its Influencing Factors.} In the previous study, Zhu et al. [28] found that FL37 normal fault passed through coal seam and was $625 \mathrm{~m}$ away from the open-off cut in the middle part of working face $2301 \mathrm{~N}$ (adjacent to the goaf, the width of the coal pillar was $3.5 \mathrm{~m}$ ) in Xinjulong Coal Mine of Heze, China. This fault had a drop of 5-6 m. The coal thickness of the working face was $9.2 \mathrm{~m}$, the dip angle was $3^{\circ}$, the buried depth was $760 \mathrm{~m}$, and the roof was composed of siltstone with a thickness of $9.5 \mathrm{~m}$. Affected by the syncline structure, the horizontal tectonic stress of the Xinjulong minefield was large, and the abutment stress was $37.6 \mathrm{MPa}$. The results of microseismic monitoring showed that the maximum activation distance of FL37 fault was $275 \mathrm{~m}$. In other studies, Jiang et al. [29] reported that NH72 normal fault existed in working face 1409 (adjacent to the goaf, sectional coal pillar width of $5 \mathrm{~m}$ ) in Huafeng Coal Mine, Xinwen, China. The drop of fault was $3.1 \mathrm{~m}-5.7 \mathrm{~m}$, the coal thickness of the working face was $6.2 \mathrm{~m}$, the dip angle was $7^{\circ}$, and the buried depth was $900 \mathrm{~m}$. The coarse-grained sandstone and mudstone were interbedded in the roof with high hardness. The results of microseismic monitoring showed that the maximum activation distance of the $\mathrm{NH} 72$ fault was $350 \mathrm{~m}$.

The working face 14310 of Dongtan Coal Mine was also adjacent to the goaf, and the width of the coal pillar was $3.5 \mathrm{~m}$, which had similar features as the above working face. The drop of the NF6 fault was $2.8 \mathrm{~m}-3.4 \mathrm{~m}$, the coal thickness of the working face was $9 \mathrm{~m}$, the dip angle was $3^{\circ}$, and the buried depth was $605 \mathrm{~m}$. The roof was composed of siltstone and medium-grained sandstone with a thickness of more than $20 \mathrm{~m}$. Microseismic monitoring results showed that the maximum activation distance of the NF6 fault was $178 \mathrm{~m}$. Comparing the fault activation laws of Dongtan Coal Mine and Xinjulong Coal Mine, it can be seen that the mining depth and fault drop of Xinjulong Coal Mine were larger than those of Dongtan Coal Mine, and other factors were similar. It indicates that fault activation was affected by fault drop and buried depth of coal seams (expressed as in situ stress). Through the comparison of fault activation law in the two mines, the mining thickness of working face 14310 in Dongtan Coal Mine was larger than that in working face 1409 of Huafeng Coal Mine, and the fault drop difference between the two working faces was not obvious. However, the fault activation distance of Dongtan Coal Mine was $172 \mathrm{~m}$ smaller than that of Huafeng Coal Mine. Although the fault drop and mining depth of 1409 working face in Huafeng Coal Mine were larger than those in working face 14310 of Dongtan Coal Mine, there may be other factors affecting the fault activation, such as the hardness and structure of roof and floor strata. Huafeng Coal Mine was a typical "three hard" (hard coal seam, hard roof, and hard floor) strata structure. The roof was a huge thick conglomerate. When the fault was formed, the thick and hard bedrock can accumulate more tectonic stress. Under the influence of mining, the stress release intensity of the fault was large, resulting in the maximum fault activation distance. Through the comparison, except for the thickness of the coal seam and roof strata structure, other conditions were similar in Xinjulong Coal Mine and Huafeng Coal Mine. However, the fault activation distance of the Xinjulong Coal Mine was $75 \mathrm{~m}$, which was smaller than that of the Huafeng Coal Mine. It indicates that the mining thickness of coal seam also has a certain influence on fault activation. In conclusion, the maximum activation distance of the mininginduced fault is affected by many factors, such as roof structure, coal thickness, fault drop, and mining depth. The influence degree of each factor on fault activation needs to be studied, and it is speculated that roof structure has a greater influence on fault activation. 


\section{Stress Evolution Law of Rock Mass under Crossing Fault Mining}

3.1. Establishment of the Numerical Model. The evolution law of stress and displacement of rock mass adjacent to the fault can effectively reflect the activation characteristics of fault structure [30]. In this section, the activation characteristics of the fault were analyzed according to the evolution law of fault stress and displacement field at different advancing positions, and the accuracy of the microseismic monitoring results in the previous section was verified. Based on the mining in working face 14310 crossing the NF6 fault, FLAC 3D software was used to establish the numerical model. The size of the model was $502.9 \mathrm{~m}$ (length) $\times 360 \mathrm{~m}$ (width) $\times 140.5 \mathrm{~m}$ (height). The fault plane was simulated by the contact surface, and both sides of the contact surface were allowed to squeeze and stagger. The fault dip angle was set at $60^{\circ}$, and the drop was $3.2 \mathrm{~m}$. The four sides and the bottom of the model were fixed constraints. The top of the model was applied with a uniform load of 11.5 MPa. The horizontal stress of 9.5 MPa and $19.5 \mathrm{MPa}$ was applied in $X$ and $Y$ directions, respectively. The Mohr-Coulomb yield criterion was used for the calculation. In the establishment of the model, some thin strata were incorporated. Table 1 shows the physical and mechanical parameters of surrounding rock, and Figure 5 shows the detailed model. Before calculation, three stress and displacement monitoring points were set on the fault plane in the middle of the $Y$-axis of the model. Precisely, there were two roof monitoring points with a vertical distance of $30 \mathrm{~m}$ (monitoring point a) and $10 \mathrm{~m}$ (monitoring point $B$ ) to the coal seam, and one bottom plate with a vertical distance of $10 \mathrm{~m}$ (monitoring point $\mathrm{C}$ ) to the fault. Figure 6 shows the established numerical model.

3.2. Results and Discussion. Figure 7 shows the abutment stress evolution in the middle of the working face from $60 \mathrm{~m}$ to $-40 \mathrm{~m}$ from the fault, and the positive and negative values represent the distance from the coal wall to the fault and passing through the fault. When the coal wall was $60 \mathrm{~m}$ away from the fault (Figure 7(a)), the fault has been activated, but the stress concentration was not high, and the hanging wall stress distribution was not affected; when the coal wall was $40 \mathrm{~m}$ away from the fault (Figure 7(b)), the vertical stress of the fault pillar and fault plane increased, and the stress isoline was distributed along the fault plane. It indicates that the fault plane has cutoff the stress transmission to a certain extent, showing the significant blocking effect of the stress. This phenomenon still existed in subsequent mining (Figures $7(\mathrm{c})-7(\mathrm{f})$ ). When the coal wall was $20 \mathrm{~m}$ away from the fault (Figure 7(c)), the stress in the fault pillar increased again. This indicates that both fault activation and roof gravity have a great influence, which is consistent with the results of microseismic monitoring. When the working face was advanced through the fault (Figure $7(\mathrm{~d})$ ), the stress concentration near the fault decreased, and the fault pillar disappeared, and the fault stress was released to a large extent. After the working face was advanced through the fault (Figures 7(e) and 7(f)), the stress distribution gradually returned to normal and the rockburst risk decreased.

Figure 8 shows the vertical stress and displacement curve of monitoring points when the working face was advanced to different positions. It can be seen that both stress and displacement increased significantly after the working face was advanced to $60 \mathrm{~m}$ from the fault. It indicates that the fault activity was obviously enhanced at this time, which is consistent with the results of microseismic monitoring (in actual mining, a large number of high-energy microseisms appeared near the fault after the working face was $62 \mathrm{~m}$ away from the fault). In addition, the stress and displacement of monitoring points in the roof were more significant than that in the floor, indicating that the mining activation degree of the roof was greater than that of the floor. When the working face was about $20 \mathrm{~m}$ away from the fault, the stress value of the monitoring point reached the maximum, and the displacement change rate (displacement curve slope) also reached the maximum synchronously. It indicated that the fault activation degree was the largest at this moment. After the working face passes through the fault, the stress and displacement of the monitoring point gradually tended to be stable, and the impact risk was reduced.

\section{Mechanism of Rockburst Induced by Fault Activation}

4.1. Conceptual Model. The fault is the product of geological movement. When the fault is formed, a large amount of tectonic stress which is mainly composed of horizontal stress accumulates in the hanging wall and footwall. When the fault is not affected by mining, the fault is in a mechanical equilibrium state. After the fault activation, the stress is released and superimposed with the mining stress. According to the periodical appearance law of microseisms in the working face and the summary of field investigation, three conceptual models are proposed for the mechanism of rockburst induced by fault activation in different stages, as shown in Figure 9.

(1) Model A: As shown in Figure 9(a), in the stage of the fault stress transfer, under the influence of mining, the fault is activated, and the accumulated horizontal stress near the fault is forced to transfer to the mining space. The strength of fault stress transfer is controlled by mining intensity, coal seam thickness, and fault mechanical properties. Fault stress is mostly transferred in the form of dynamic load and superimposed with the advance support pressure of the working face, which may trigger burst failure of rock mass in the local and critical stable state. In this stage, the distance between the working face and the fault is relatively far, and the fault stress transfer is accompanied by a certain degree of attenuation, so the strength of rockburst is usually small, and the location of rockburst mostly occurs in the peak stress area in front of the working face.

(2) Model B: As shown in Figure 9(b), in the stage of fault pillar stress behavior, the fault pillar is formed 
TABle 1: Physical and mechanical parameters of surrounding rock.

\begin{tabular}{lccccccc}
\hline Location & Lithology & $\begin{array}{c}\text { Thickness } \\
(\mathrm{m})\end{array}$ & $\begin{array}{c}\text { Shear modulus } \\
(\mathrm{GPa})\end{array}$ & $\begin{array}{c}\text { Bulk modulus } \\
(\mathrm{GPa})\end{array}$ & $\begin{array}{c}\text { Density } \\
\left(\mathrm{kg} \cdot \mathrm{m}^{-3}\right)\end{array}$ & $\begin{array}{c}\text { Cohesion } \\
(\mathrm{MPa})\end{array}$ & $\begin{array}{c}\text { Internal friction } \\
\mathrm{angle}\left({ }^{\circ}\right)\end{array}$ \\
\hline Main roof & $\begin{array}{c}\text { Medium-grained } \\
\text { sandstone }\end{array}$ & 48.74 & 13.12 & 15.71 & 2500 & 5.4 & 35 \\
$\begin{array}{l}\text { Immediate } \\
\text { roof }\end{array}$ & Siltstone & 21.67 & 4.64 & 4.38 & 2600 & 1.1 & 33 \\
$\begin{array}{l}\text { Working face } \\
\text { Immediate }\end{array}$ & $\begin{array}{c}\text { Coal seam } \\
\text { Medium-grained } \\
\text { sloor }\end{array}$ & 9.00 & 0.38 & 0.55 & 1350 & 0.9 & 3.4 \\
Main roof & $\begin{array}{c}\text { Coarse-grained } \\
\text { sandstone }\end{array}$ & 39.50 & 15.65 & 13.12 & 15.71 & 2500 & 35 \\
\hline
\end{tabular}

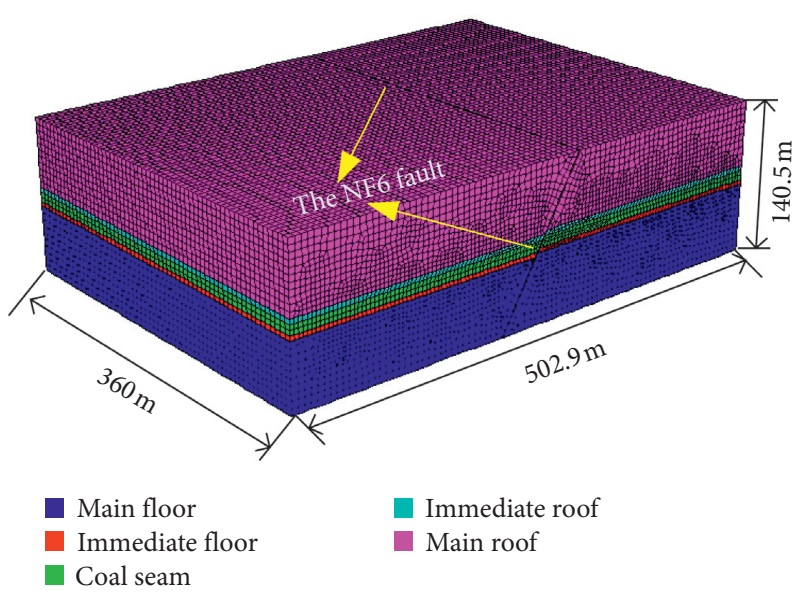

FIGURE 6: Numerical simulation model.

due to the fault cutting off the continuity of the coal seam and roof and floor. Under the double action of rotary subsidence of the roof rock and advance support pressure, the static load stress of the fault pillar is highly concentrated. With the continuous decrease in the width of the fault pillar, the accumulated elastic energy in the coal pillar is much greater. At this time, the dynamic load of fault activation is superimposed with accumulated elastic energy. Under the influence of multiple factors, the fault pillar is prone to rockburst with a large damage degree. Therefore, this stage is the key to fault rockburst prevention and control.

(3) Model C: As shown in Figure 9(c), in the stage of fault structure activation, the distance between the fault and the working face is small. In addition, the fault has experienced long-term activation, the sliding property of the cross-section is enhanced, and the relative movement trend of the hanging wall and footwall of the fault increases under the action of roof pressure, resulting in the increasing risk of rockburst. In this stage, the rockburst strength is larger than that in the stage of the fault stress transfer and is smaller than that in the stage of the fault pillar stress behavior. The location of rockburst mostly occurs near the fault.
4.2. Mechanical Mechanism. According to the conceptual model of rockburst induced by fault activation, the rockburst carrier system model of "roof-coal seam-floor" near the fault was established, as shown in Figure 10. When coal seam is mined near the fault, the fault pillar bears the high static load, and its stress-strain relationship is described by the curve on the right side in Figure 10. Meanwhile, the roof and floor are regarded as complete surrounding rock, and its stiffness and strength are far greater than that of coal seam, and its load-bearing stress-strain relationship is described by the curve on the left side of Figure 10.

Under the action of the static load $\left(\sigma_{\mathrm{s}}\right)$, when the coal seam in the postpeak stage $(D E)$ produces strain increment $\Delta \varepsilon_{2}$, the corresponding strain increment $\Delta \varepsilon_{1}$ in surrounding rock of the roof and floor is

$$
\Delta \varepsilon_{1}=\frac{k_{2}}{k_{1}} \Delta \varepsilon_{2},
$$

where $k_{1}$ is the prepeak loading stiffness of surrounding rock, and $k_{2}$ is the postpeak unloading stiffness of coal seam.

Therefore, the total strain increment $\Delta \varepsilon$ of the roof-coal seam-floor system is as follows:

$$
\Delta \varepsilon=\Delta \varepsilon_{1}+\Delta \varepsilon_{2}=\frac{k_{1}+k_{2}}{k_{1}} \Delta \varepsilon_{2} .
$$

Among them, the ratio of coal seam strain increment to system overall strain increment is

$$
\frac{\Delta \varepsilon_{2}}{\Delta \varepsilon}=\frac{k_{1}}{k_{1}+k_{2}} \text {. }
$$

When $k_{1}+k_{2}=0$, the stress state of the coal rock corresponds to point $S_{1}$ in Figure 10. At this time, $\Delta \varepsilon_{2} / \Delta \varepsilon \longrightarrow \infty$, and the rockburst is started. As the coal impact damage gradually decreases, the roof-coal seam-floor system gradually reaches a new balance, corresponding to point $S$ in Figure 10. Finally, the rockburst process ends.

The energy forms in the abovementioned impact process include the consumption of energy by coal seam before the burst $\left(U_{D B}^{C}\right)$, the consumption of elastic energy stored in coal seams during the burst process $\left(U_{D D}^{C}\right)$, the consumption of the elastic energy released by coal seam to surrounding rock during the burst process $\left(U_{D D}^{R}\right)$, the residual elastic energy released by the system during the burst process $\left(U_{R}\right)$, the elastic energy released by surrounding rock during the burst 


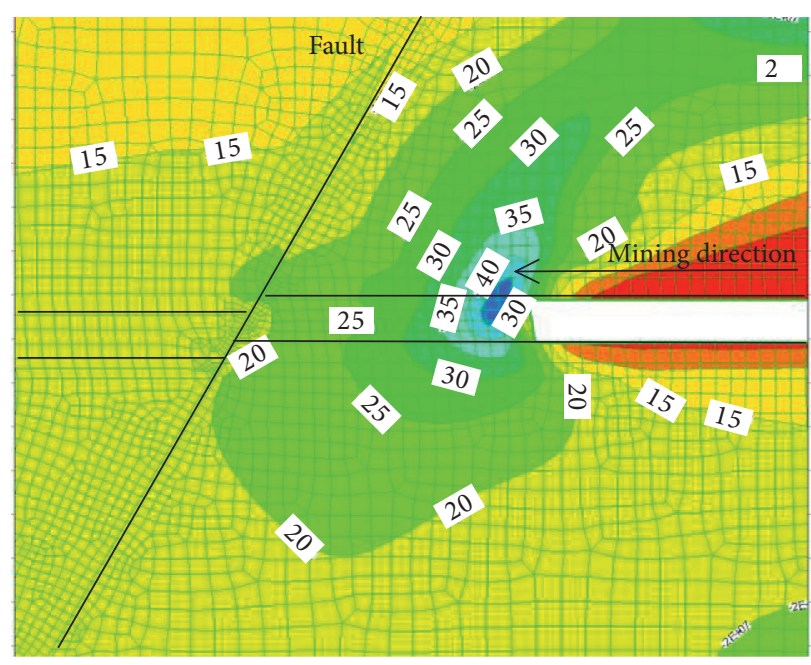

(a)

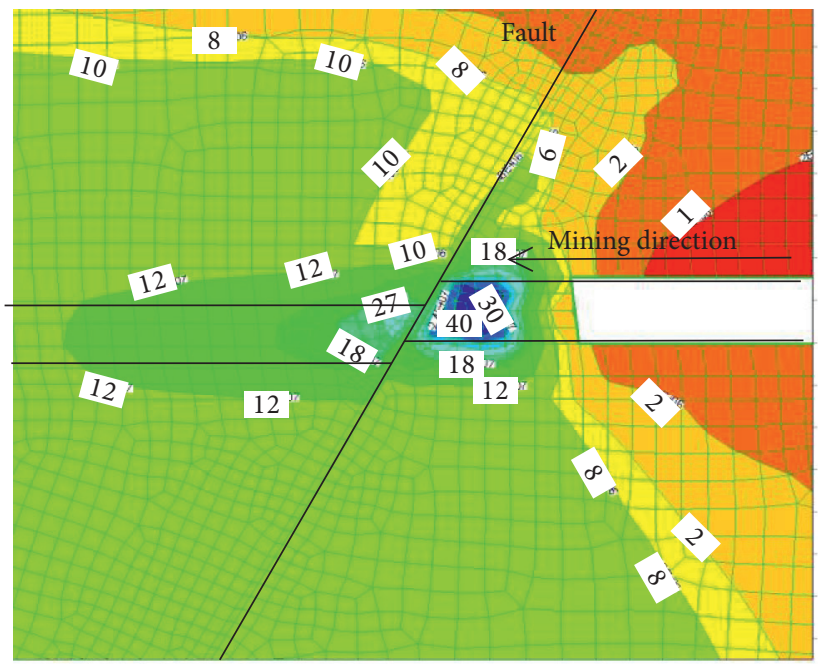

(c)

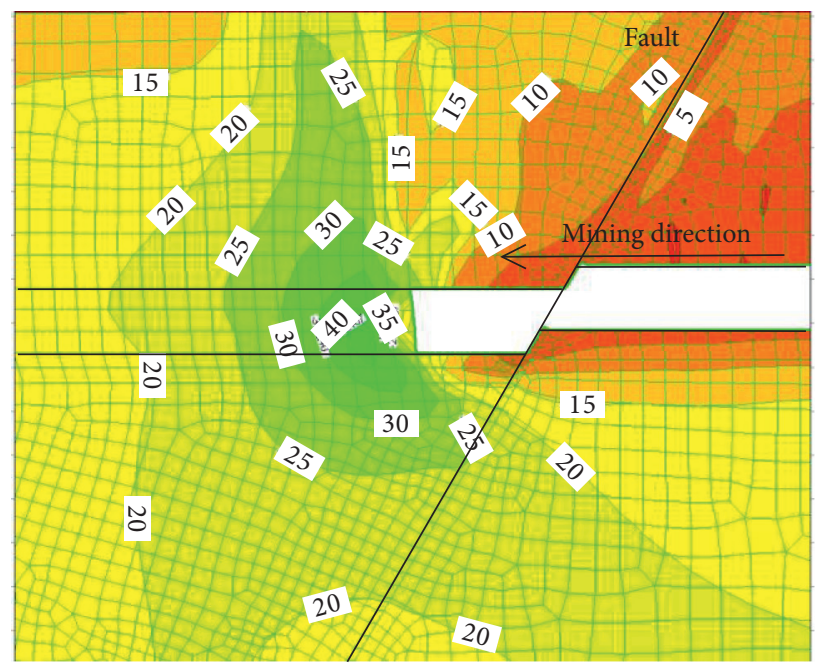

(e)

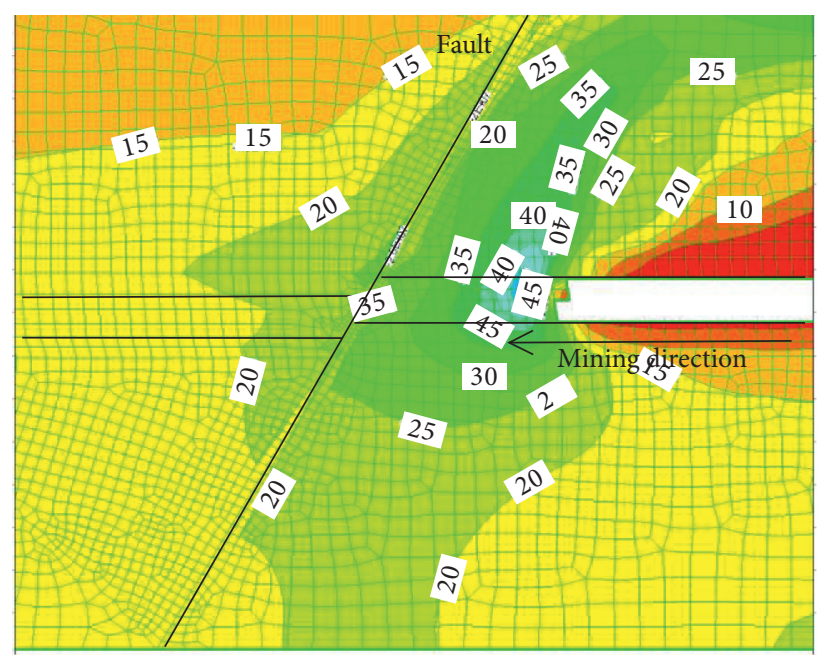

(b)

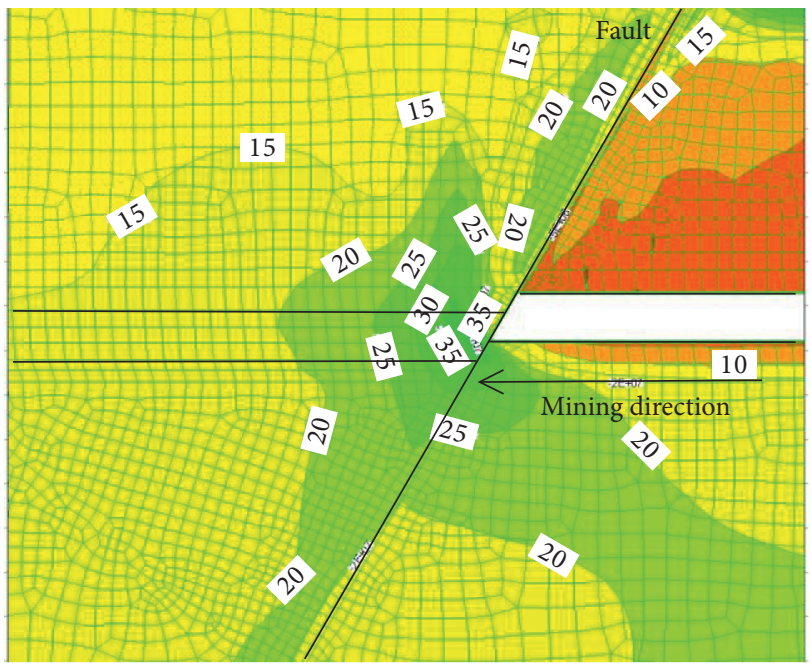

(d)

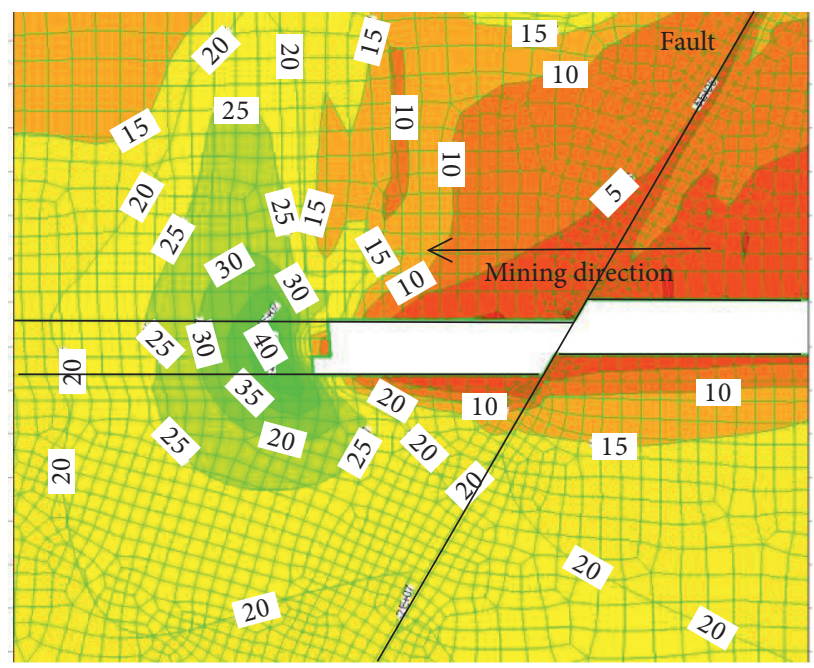

(f)

FIGURE 7: Distribution of vertical stress during fault-crossing mining (MPa). (a) $60 \mathrm{~m}$. (b) $40 \mathrm{~m}$. (c) $20 \mathrm{~m}$. (d) $0 \mathrm{~m}$. (e) -20 m. (f) -40 m. 


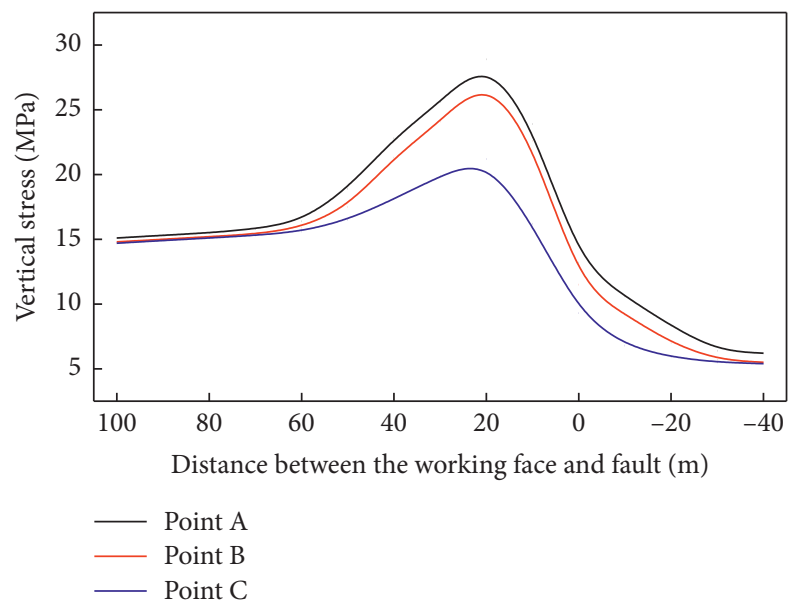

(a)

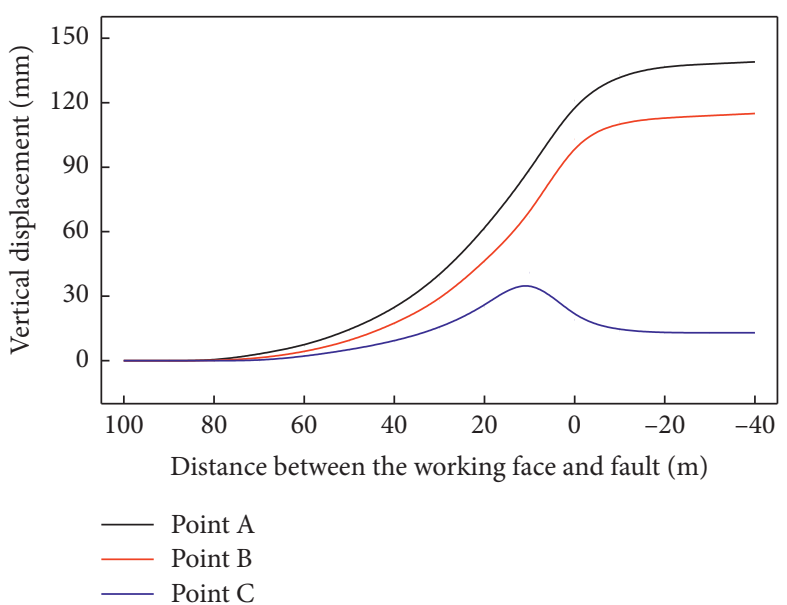

(b)

Figure 8: Change curves of vertical stress and displacement of fault plane with the mining progress. (a) Vertical stress. (b) Vertical displacement.

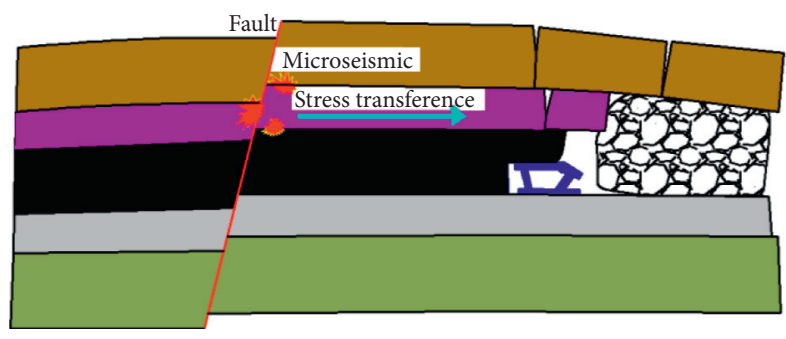

(a)

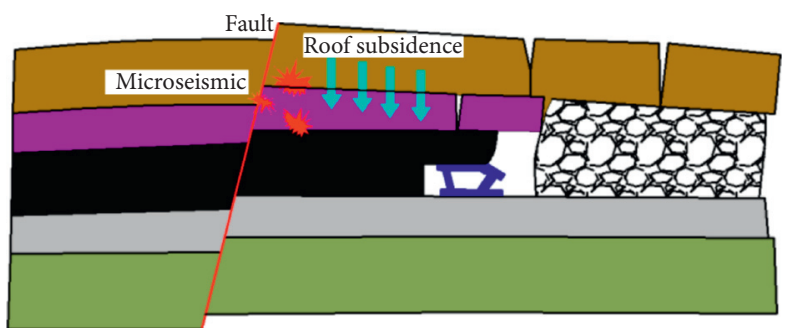

(b)

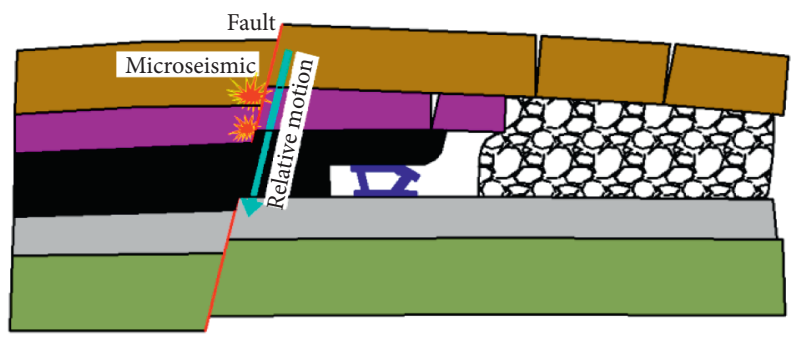

(c)

Figure 9: Conceptual model of rockburst induced by fault activation. (a) Model A. (b) Model B. (c) Model C.

process $\left(U_{E}^{R}\right)$, and the residual elastic performance stored in coal seam after the burst process $\left(U_{E}\right)$.

When the rockburst carrier system of "roof-coal seamfloor" near the fault is superimposed with the dynamic load of fault activation $\left(\sigma_{d}\right)$, compared with the impact energy release $\left(U_{R}\right)$ under the static load, the energy release $\left(\Delta U_{R}\right)$ increases, as shown in Figure 10. At this time, it is equivalent to that the stiffness of surrounding rock is reduced from $k_{1}$ to $k_{1}^{\prime}$, and the starting position of impact is advanced from $S_{1}$ to $S_{2}$. In addition, the dynamic loading mode of fault activation is equivalent to cyclic loading and unloading, leading to permanent deformation of the coal body. Therefore, when the action time of dynamic loading is long enough, for the coal in the stress state $S_{2}^{\prime}$ under the superimposed dynamic loading, the impact condition similar to the stress state of $S_{2}$ under the static loading can be started. In a word, the mechanism of fault rockburst can be summarized as the superposition of the high static load of the fault pillar and dynamic load of fault activation. The high static load of the fault pillar is caused by the action of the advanced pressure and roof structure.

\section{Monitoring and Prevention of Rockburst Induced by Fault Activation}

5.1. Monitoring and Prevention Measures. According to the fault activation mechanism, the monitoring and prevention of fault rockburst should be carried out from the monitoring and characterization of fault rockburst and attenuation of the high static load of the fault pillar and dynamic load of 


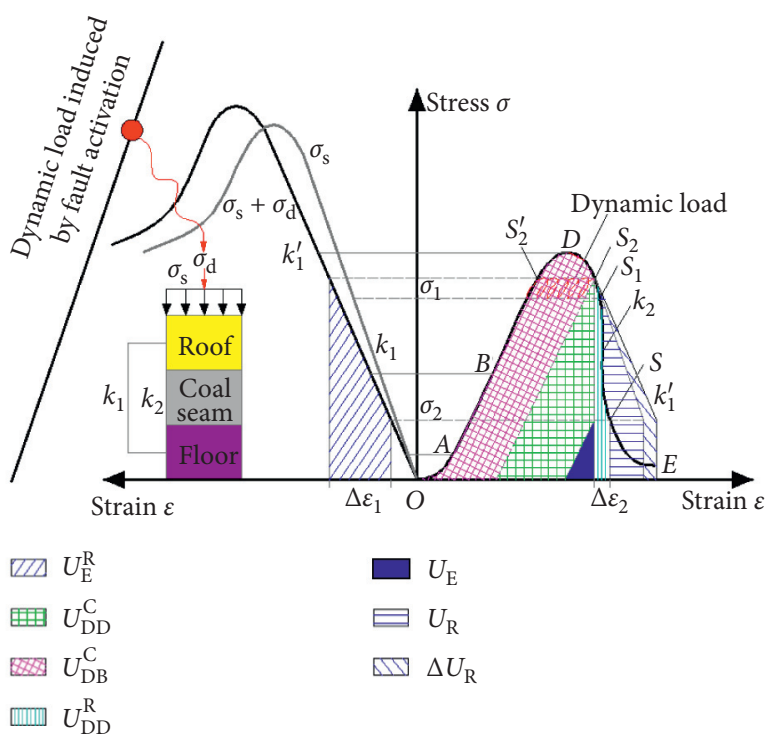

FIgURE 10: The mechanism of rockburst induced by fault reactivation.

fault activation. To monitor the static load of the fault pillar, the stress and fracture information between the fault and working face can be directly obtained by the drilling cuttings method, borehole stress, microseismic monitoring, surface displacement, and other conventional methods; roof movement and overlying rock structure evolution information can be inferred by using support working resistance monitoring, and coal pillar static load information under the coupling effect of the fault and roof structure can also be obtained indirectly. To monitor the dynamic load of fault activation, the microseismic monitoring method is mainly used. Large diameter borehole pressure relief, deep hole pressure relief blasting, and roadway reinforcement support can be used to prevent and control high static load of the fault pillar. To prevent and control the dynamic load of fault activation, methods such as large diameter borehole pressure relief and water injection can be used to directly reduce the cohesive force and friction angle of the fault plane, so as to weaken the release strength of the dynamic load of fault activation. Besides, the mining speed of the working face can be controlled to reduce the intensity of fault disturbance. In addition, reinforcement support is also an effective in situ anti-impact method, which can provide higher lateral constraints for the roadway side and improve the compression strength and anti-impact ability of coal in the fault area. Based on the above concept and technology of erosion prevention, a microseismic system was installed before the mining of working face 14310 to monitor the fracture information of surrounding rock during the mining, and the following prevention measures were implemented.

5.1.1. Coal Seam Water Injection. Before mining, six water injection drilling fields were arranged in roadways with a spacing of $90 \mathrm{~m}$. Six boreholes were arranged in a single row along the coal seam in a radial manner. The horizontal angle of the boreholes was $25^{\circ}$, the depth of the boreholes was $75 \mathrm{~m}$, the diameter of the boreholes was $100 \mathrm{~m}$, the highpressure water injection pressure was $16 \mathrm{MPa}$, and the static pressure water injection pressure was $5 \mathrm{MPa}$. After water injection, the measured value of water content of coal increased from $5.4 \%$ to $8.9 \%$, and the effect of water injection was significant.

5.1.2. Large Diameter Borehole Pressure Relief. When the working face was $350 \mathrm{~m}$ away from the fault, large diameter boreholes were used to relieve pressure in the mining roadway $150 \mathrm{~m}$ in front of the fault and $80 \mathrm{~m}$ behind the fault, with a hole diameter of $130 \mathrm{~m}$, a hole depth of $25 \mathrm{~m}$, and a spacing of $2 \mathrm{~m}$. After pressure relief, the roadway in this range was reinforced by adding a bolt between the original two bolts.

5.1.3. The Reduction of the Mining Speed. When the distance between the working face and the fault was $150 \mathrm{~m}$, the mining speed of the working face was adjusted from $5.8-7.6 \mathrm{~m} / \mathrm{d}$ to $3.8-4.5 \mathrm{~m} / \mathrm{d}$, and the mining was kept at a constant speed. When the working face was $60 \mathrm{~m}$ away from the fault, the mining speed was strictly controlled below $3.5 \mathrm{~m} / \mathrm{d}$. In addition, the drilling cuttings method was used to detect the $100 \mathrm{~m}$ roadway in front of the working face in real time. Only when the amount of drilling cuttings did not exceed the standard, the working face can continue to advance.

5.2. Prevention and Control Effect. When the working face was $175 \mathrm{~m}$ away from the fault, the microseism with the vibration energy of $8.28 \times 10^{4} \mathrm{~J}$ was detected by the microseismic system. The roadway side displacement of the tailentry was obvious at about $35 \mathrm{~m}$ in front of the working face. The floor heaved, the belt frame was lifted, and part of the bolts failed, as shown in Figure 11. There was no major equipment damage or casualties in this incident, but it played a warning role for the subsequent mining of the working face. Besides, it is shown that the intensity of rockburst can be reduced effectively by adopting water injection in the early stage of coal seam. After that, the large diameter borehole pressure relief and mining speed reduction measures were implemented in the working face. When the working face was pushed to about $75 \mathrm{~m}$ away from the fault, the microseismic system detected three consecutive vibration events with energy greater than $10^{4} \mathrm{~J}$ near the fault. Almost no deformation and failure occurred in the roadway, and the mining production was not affected. It shows that the measures of large diameter borehole pressure relief and the reduction of the mining speed can be used to effectively improve the pressure behavior of roadway and mine pressure. In addition, the combination of water injection in coal seam before the mining, large diameter borehole pressure relief, and the reduction of the mining speed can effectively control the fault-type rockburst hazard. Finally, safe crossing fault mining was realized in working face 14310, and the goal of earthquake prevention and disaster-free was achieved. 


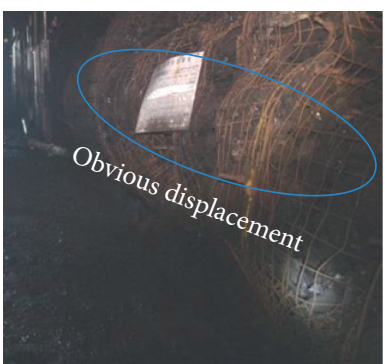

(a)

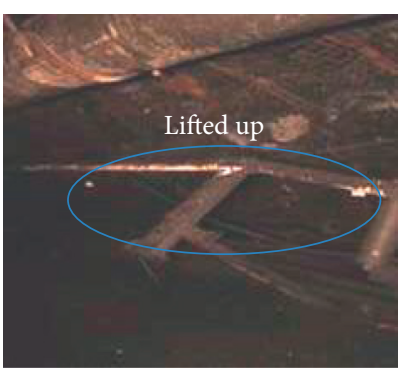

(b)
FIGURE 11: Damaged condition of the roadway.

\section{Conclusions}

To reduce the frequency of rockburst in the fault area, the research on fault activation law and the rockburst induced mechanism in the deep working face of the crossing fault mining was carried out by theoretical analysis, microseismic monitoring, numerical simulation, and engineering practice. Besides, the prevention concept and technical measures were put forward for preventing such rockburst. The main research conclusions are as follows:

(1) Based on the microseismic source location, frequency, and energy behavior law during faultcrossing mining, the distance between the working face and fault is used to divide the fault activation degree into three stages: fault stress transfer, fault pillar stress behavior, and fault structure activation. It is found that in the stage of fault pillar stress behavior, there is the largest possibility of impact disaster with the highest intensity. This finding is also verified by numerical simulation. Combined with the engineering practice, the influence factors of fault activation degree are compared and discussed. Among many factors, roof structure of the rock mass has a greater influence on fault activation distance.

(2) Combined with periodic appearance law of microseisms in the fault area, mining stress distribution law, and related field investigation, conceptual models of fault-type rockburst in three types are proposed. Besides, based on the rock mechanics theory, the rockburst carrier system model of "roofcoal seam-floor" in the fault area is established. The mechanical essence of fault-type rockburst is obtained as follows: under the action of fault structure, the static load of the fault coal pillar is increased and superimposed with the active dynamic load of the fault, leading to high-strength impact disaster.

(3) Based on the induced mechanism of fault rockburst, the concept of fault rockburst monitoring and prevention is proposed. Specifically, the monitoring and prevention of fault rockburst should start from two aspects: the monitoring and characterization of fault rockburst and the weakening control of the high static load and fault dynamic load of the fault coal pillar. In addition, the targeted technical measures are proposed. The engineering practice in 14310 working face of Dongtan Coal Mine has proved that the concept has a significant effect on the prevention and control of fault-type rockburst.

\section{Nomenclature}

$\Delta \varepsilon_{1}:$ Strain increment in surrounding rock of the roof and floor

$\Delta \varepsilon_{2}: \quad$ Strain increment in coal seam

$\Delta \varepsilon: \quad$ Total strain increment of the roof-coal seam-floor system

$k_{1}$ : $\quad$ Prepeak loading stiffness of surrounding rock

$k_{2}$ : $\quad$ Postpeak unloading stiffness of coal seam

$U_{D B}^{C}$ : Consumption of energy by coal seam before the burst

$U_{D D}^{C}$ : Consumption of elastic energy stored in coal seams during the burst process

$U_{D D}^{R}$ : Consumption of elastic energy released by coal seam to the surrounding rock during the burst process

$U_{R}$ : Residual elastic energy released by the system during the burst process

$U_{E}^{R}$ : Elastic energy released by the surrounding rock during the burst process

$U_{E}$ : Residual elastic performance stored in the coal seam after the burst process

$\Delta U_{R}$ : Increase of energy release.

\section{Data Availability}

The date used to support the findings of this study are available from the corresponding author upon request.

\section{Conflicts of Interest}

The authors declare that they have no conflicts of interest.

\section{Acknowledgments}

This study was supported by the National Natural Science Foundation of China (51604139), the Natural Science Foundation of Inner Mongolia Autonomous Region (2019LH05005), and the Innovation Foundation of Inner Mongolia University of Science and Technology (2019QDLB32).

\section{References}

[1] H. Rong, S. Q. Yu, H. W. Zhang, and B. Liang, "Quantitative calculation of critical depth in typical rockburst mine," Advances in Civil Engineering, vol. 2020, Article ID 7968160, 9 pages, 2020.

[2] A.-Y. Cao, L.-M. Dou, C.-B. Wang, X.-X. Yao, J.-Y. Dong, and $\mathrm{Y}$. Gu, "Microseismic precursory characteristics of rock burst hazard in mining areas near a large residual coal pillar: a case study from Xuzhuang coal mine," Rock Mechanics and Rock Engineering, vol. 49, no. 11, pp. 4407-4422, 2016.

[3] Z. K. Zhang, L. G. Wang, R. L. Shan, and Y. L. Lu, "Support technology of high resistant and yielding property for deep roadway under dynamic pressure," Journal of Mining and Safety Engineering, vol. 29, no. 1, pp. 33-37, 2012. 
[4] J. S. Guo, L. Q. Ma, F. Ju, C. G. Zhang, F. T. Wang, and S. Guo, "Mechanism of dynamic failure in roadways with thick and competent roof strata: a case study," Advances in Civil Engineering, vol. 2019, Article ID 2618543, 15 pages, 2019.

[5] A. Sainoki and H. S. Mitri, "Dynamic modeling of fault slip induced by stress waves due to stope production blasts," Rock Mechanics and Rock Engineering, vol. 49, no. 1, pp. 165-181, 2016.

[6] L. Jiang, Q. Wu, Q. Wu et al., "Fracture failure analysis of hard and thick key layer and its dynamic response characteristics," Engineering Failure Analysis, vol. 98, pp. 118-130, 2019.

[7] C.-P. Lu, Y. Liu, N. Zhang, T.-B. Zhao, and H.-Y. Wang, "Insitu and experimental investigations of rockburst precursor and prevention induced by fault slip," International Journal of Rock Mechanics and Mining Sciences, vol. 108, pp. 86-95, 2018.

[8] B. Orlic and B. B. T. Wassing, "A study of stress change and fault slip in producing gas reservoirs overlain by elastic and viscoelastic caprocks," Rock Mechanics and Rock Engineering, vol. 46, no. 3, pp. 421-435, 2013.

[9] A. E. Hatem, M. L. Cooke, and K. Toeneboehn, "Strain localization and evolving kinematic efficiency of initiating strike-slip faults within wet kaolin experiments," Journal of Structural Geology, vol. 101, pp. 96-108, 2017.

[10] Q. Jiang, B. Yang, F. Yan, C. Liu, Y. G. Shi, and L. F. Li, "New method for characterizing the shear damage of natural rock joint based on 3D engraving and 3D scanning," International Journal of Geomechanics, vol. 20, no. 2, Article ID 06019022, 2020.

[11] Q. Jiang, F. Yan, J. Wu, Q. Fan, S. Li, and D. Xu, "Grading opening and shearing deformation of deep outward-dip shear belts inside high slope: a case study," Engineering Geology, vol. 250, pp. 113-129, 2019.

[12] Q. X. Qi, Y. W. Shi, and T. Q. Liu, "Mechanism of instability caused by viscous sliding in rock burst," Journal of China Coal Society, vol. 22, no. 2, pp. 144-148, 1997.

[13] L. Dai, Y. Pan, A. Wang, Y. Xiao, and X. Ma, "Experimental study on the self-protection performance of anchor bolts with energy-absorbing tails," Rock Mechanics and Rock Engineering, vol. 53, no. 5, pp. 2249-2263, 2020.

[14] H. Rong, B. Liang, H. W. Zhang, and F. Zhu, "Research on structural characteristics of dynamic nuclear zone in dynamic system of coal and rock," Advances in Civil Engineering, vol. 2019, Article ID 4815236, 10 pages, 2019.

[15] S. Zhu, Y. Feng, and F. Jiang, "Determination of abutment pressure in coal mines with extremely thick alluvium stratum: a typical kind of rockburst mines in China," Rock Mechanics and Rock Engineering, vol. 49, no. 5, pp. 1943-1952, 2016.

[16] X. Si and F. Gong, "Strength-weakening effect and sheartension failure mode transformation mechanism of rockburst for fine-grained granite under triaxial unloading compression," International Journal of Rock Mechanics and Mining Sciences, vol. 131, Article ID 104347, 2020.

[17] F.-q. Gong, X.-f. Si, X.-b. Li, and S.-y. Wang, "Experimental investigation of strain rockburst in circular caverns under deep three-dimensional high-stress conditions," Rock Mechanics and Rock Engineering, vol. 52, no. 5, pp. 1459-1474, 2019.

[18] A. Manouchehrian and M. Cai, "Numerical modeling of rockburst near fault zones in deep tunnels," Tunnelling and Underground Space Technology, vol. 80, pp. 164-180, 2018.

[19] L. Jiang, P. Wang, P. Zhang, P. Zheng, and B. Xu, "Numerical analysis of the effects induced by normal faults and dip angles on rock bursts," Comptes Rendus Mécanique, vol. 345, no. 10, pp. 690-705, 2017.

[20] L. S. Jiang, P. Wang, P. Q. Zheng, H. J. Luan, and C. Zhang, "Influence of different advancing directions on mining effect caused by a fault," Advances in Civil Engineering, vol. 2019, Article ID 7306850, 10 pages, 2019.

[21] P. Wang, L. S. Jiang, P. Q. Zheng, C. P. Qin, and C. Zhang, "Inducing mode analysis of rock burst in fault-affected zone with a hard-thick stratum occurrence," Environmental Earth Sciences, vol. 78, no. 15, 2019.

[22] J. Q. Jiang, P. Wang, L. S. Jiang, P. Q. Zheng, and F. Feng, "Numerical simulation on mining effect influenced by a normal fault and its induced effect on rock burst," Geomechanics and Engineering, vol. 14, no. 4, pp. 337-344, 2018.

[23] H. Luo, Z. H. Li, A. W. Wang, and Y. H. Xiao, "Study on theevolution law of stress field when approaching fault in deep mining," Journal of China Coal Society, vol. 39, no. 2, pp. 322-327, 2014.

[24] R. S. Michael and J. Thomas, "Fault induced rock bursts and micro-tremors - experiences from the Gotthard Base Tunnel," Tunnelling and Underground Space Technology, vol. 81, pp. 358-366, 2018.

[25] K. Ma, F. Z. Yuan, D. Y. Zhuang, Q. S. Li, and Z. W. Wang, "Study on rules of fault stress variation based on microseismic monitoring and numerical simulation at the working face in the Dongjiahe Coal Mine," Shock and Vibration, vol. 2019, Article ID 7042934, 12 pages, 2019.

[26] J. He, L. Dou, S. Gong, J. Li, and Z. Ma, "Rock burst assessment and prediction by dynamic and static stress analysis based on micro-seismic monitoring," International Journal of Rock Mechanics and Mining Sciences, vol. 93, pp. 46-53, 2017.

[27] J. He, L.-M. Dou, Z.-L. Mu, A.-Y. Cao, and S.-Y. Gong, "Numerical simulation study on hard-thick roof inducing rock burst in coal mine," Journal of Central South University, vol. 23, no. 9, pp. 2314-2320, 2016.

[28] S. T. Zhu, F. X. Jiang, K. J. A. Kouame et al., "Fault activation of fully mechanized caving face in extra-thick coal seam of deep shaft," Chinese Journal of Rock Mechanics and Engineering, vol. 35, no. 1, pp. 50-58, 2016.

[29] F. X. Jiang, S. H. Yang, Y. H. Cheng, X. G. Zhang, Z. Y. Mao, and F. J. Xu, "A study on microseismic monitoring of rock burst in coal mine," Chinese Journal of Geophysics, vol. 49, no. 5, pp. 1511-1516, 2006.

[30] Q. Jiang, G. Su, X.-t. Feng, G. Chen, M.-z. Zhang, and C. Liu, "Excavation optimization and stability analysis for large underground caverns under high geostress: a case study of the Chinese Laxiwa project," Rock Mechanics and Rock Engineering, vol. 52, no. 3, pp. 895-915, 2019. 